\title{
História e Historiografia da Educação Física: concepções e métodos de pesquisa
}

\author{
History and Historiography of Physical Education: \\ concepts and research methods
Historia y Historiografía de la Educación Física: concepciones y métodos de investigación

\author{
YCARO OliVEIRA DO GRANJA $^{1}$; BIANCA MiaRKA ${ }^{2}$
}

\section{Resumo}

Este artigo traz uma discussão sobre as diferentes abordagens e métodos de pesquisas científicas na área de História e Historiografia da Educação Física realizados no Brasil. Para isso, realizou-se a análise de trabalhos publicados em uma base eletrônica de dados, a Scientific Eletronic Library Online (SciELO). A busca foi feita com as palavras-chave e/ou termos específicos indexados: "história" e "historiografia" em combinação com o termo "Educação Física". Como resultado, foram encontradas 36 publicações, as quais mostraram que no Brasil as pesquisas trazem problemas diacromiais e semelhantes, no que se refere às modificações de métodos de ensino escolar, mudanças políticas e o foco higienista que são desafios associados à sociedade e à cultura nacional. A partir disso, foi possível traçar um panorama com discussão sobre limitações e recomendações para estudos futuros relacionados com história e historiografia da Educação Física.

Palavras-chave: História; Historiografia; Educação Física; Educação

\footnotetext{
${ }^{1}$ Graduado em Educação Física pela Universidade Federal de Pelotas. E-mail: ycarooliveira21 @ hotmail.com

${ }^{2}$ Doutora em Biodinâmica pela Escola de Educação Física e Esporte da Universidade de São Paulo, com estágio de pós-doutorado concluído na Universidade Federal de Pelotas. Professora Adjunta da Universidade Federal do Rio de Janeiro. E-mail: miarkasport@ hotmail.com
} 


\begin{abstract}
This article shows an important discussion about the different approaches and methods of scientific research in the area of history and historiography of the Physical Education in Brazil. For this, an electronic database was used, the Scientific Eletronic Library Online (SCIELO). This search was performed using keywords and specific terms indexed: "History", "historiography" in combination with the term Physical Education. As the result, a total of 36 articles were found, which show that, in Brazil, the studies show diacromial problems which refer to the teaching methods, political changes and the hygienist focus challenges associated with society and the national culture. From this, it was possible to draw a design with discussions about limitations, recommendations for future studies related to Physical Education history and historiography.
\end{abstract}

Key-words: History; Historiography; Physical Education; Education

\title{
Resumen
}

Este artículo muestra una discusión sobre los diferentes enfoques y métodos de investigación científica en el área de Historia y Historiografía de la Educación Física realizados en Brasil. Para ello, se realizó el análisis de trabajos publicados en una base electrónica de datos, la Scientific Eletronic Library Online (SciELO). La búsqueda se hizo con las palabras clave y / o términos específicos indexados: "historia" y "historiografía" en combinación con el término "Educación Física". Como resultado, se encontraron 36 publicaciones, las cuales mostraron que en Brasil las investigaciones traen problemas diacromiales y similares, en lo que se refiere a las modificaciones de métodos de enseñanza escolar, cambios políticos y el foco higienista que son desafíos asociados a la sociedad ya la cultura nacional . A partir de eso, fue posible trazar un panorama con discusión sobre limitaciones y recomendaciones para estudios futuros relacionados con historia e historiografía de la Educación Física.

Palabras-clave: Historia; la historiografía; Educación Física; educación 


\section{Introdução}

O estudo dos métodos de pesquisas históricas é realizado para compreender as técnicas e orientações que os pesquisadores usam para interpretar fontes primárias e outras provas para a investigação científica (CAMPOS; COSTA, 1977; HEROLD JUNIOR, 1997). Ademais, o estudo do método histórico e da escrita é conhecido historiografia (CAMPOS; COSTA, 1977). Nas principais revistas da Educação Física do Brasil, ou mesmo na maior parte dos jornais científicos sobre práticas físicas, os estudos históricos com suas grandes reflexões teóricas não têm sido apresentados aos leitores como deveriam e sofrem barreiras impostas por uma filosofia de "desfecho em resultados numéricos" (NUNES, 1994; HEROLD JUNIOR, 1997). Quando analisado o conjunto das fontes históricas, observa-se que as mudanças ocorridas na Educação Física (seja no âmbito cultural ou social), em direção à novas figurações, não foram racionalmente planejadas, mas também não se pode reduzir essas modificações ao aparecimento e desaparecimento aleatórios de modelos desordenados (ELIAS, 1993; BRANDÃO, 2011). Apesar da dificuldade em compreender como utilizar os métodos de pesquisa na história para compreender desde fontes primárias até narrativas consagradas, essa identificação e o conhecimento da Educação Física no passado poderia aprimorar, renovar e criar práxis comprometidas com estudos críticos e reflexivos sobre a Educação Física (DIAS, 2014; KAMINSKI; GOELLNER, 2010; MARQUES, 2009).

Heródoto e Tucídides, considerados os precursores da história estudada por métodos científicos, ficariam surpresos pelo pouco número de investigações articuladoras de diversas fontes de informação, como crônicas, gravações, e achados arqueológicos, para construir a sucessão de processos históricos dignos de uma análise crítica sobre a Educação Física. A narrativa na/da Educação Física e das práticas corporais a partir de dados concretos, assim como o estudo das formas da escrita e interpretação das fontes históricas, deveriam ser objeto de debate constante, pela própria importância, pois são conhecimentos sem os quais diferentes contextos das Ciências da Saúde não poderiam ser compreendidos diante das questões envolvidas nas próprias reconstruções históricas, isto é, diante dos modos de percepção ou representação das suas práticas em momentos e marcos históricos (MELLO, 2009; ROSÁRIO; DARIDO, 2012).

É absolutamente comum deparar-se com revisores que enumeram características singulares e faltantes, advindas de conjecturas qualitativas, em uma sucessão de "vieses padrões". Estes subjugam desde textos com semióticas sobre o significante (forma) e o significado (conteúdo) das práticas corporais, até mesmo aprofundamentos históricos sobre o desenvolvimento da Educação Física, que apresentariam não só a distribuição moderna do tempo como resultado de um exame sistemático da história, como ao que concerne ao método, espírito e à filosofia (CAMPOS; COSTA, 1977). Caracterizaria-se, assim, um volensnolens, uma atitude frente ao tempo. Os quadros novos, mais vastos e mais gerais da historiografia contemporânea da Educação Física (MARQUES, 2009), são prova de uma visão do mundo e, ao mesmo tempo, de um estado dos conhecimentos nessa área (MARQUES, 2009). 
Porém, a negligência sobre os estudos da Educação Física na área da história, como ciência que estuda a ação do ser humano no tempo e espaço concomitante à análise dos processos e eventos ocorridos no passado, causou uma consequência grave nas últimas décadas nessa área acadêmica: uma falta de interesse dos cursos Stricto Sensu em investigar as dimensões históricas das práticas corporais para investigar a Educação Física a partir de diferentes métodos históricos e das próprias narrativas. Em contrapartida, há um corpus restrito de artigos, com recortes de períodos cronológicos, nos quais a ênfase é dada em: i) ordenar razões sobre o uso das atividades corporais e explicar as origens e as mudanças políticas na Educação Física; ii) abordar modificações dos métodos e sistematizações de treinamento, e; iii) em apresentar impactos socioculturais das práticas físicas. Os assuntos dos estudos da história e historiografia da Educação Física discutem métodos ginásticos, corporeidade, preceitos higienistas, militaristas ou desportivos (ROSÁRIO; DARIDO, 2012).

Pouco se discute sobre o método da pesquisa histórica para o estudo da Educação Física (SOARES, 2011; GODOI; NEVES, 2012), o que traz um importante paradigma em relação ao entedimento contextual dos métodos e abordagens para compreensão profunda sobre temáticas que possam ser trabalhadas em futuros estudos (DEVIDE et al., 2011). Partindo dos princípios fundamentais que norteiam os métodos de pesquisa históricos, torna-se necessário realizar uma análise dos métodos e da produção publicada no país na área da Educação Física. Por isso, o objetivo desse documento é apresentar uma discussão crítica e reflexiva sobre pesquisas em história e historiografia da Educação Física e debater sobre as concepções das metodologias empregadas nas diferentes abordagens.

\section{Métodos}

Em uma revisão sobre a produção no Brasil foram recuperados dados a partir de pesquisas publicadas em revistas científicas, disponíveis física e eletronicamente (até outubro de 2015). Para isso, utilizou-se a base de dados Scientific Eletronic Library Online (SCIELO). As buscas nessa base de dados eletrônica foram realizadas empregando as seguintes palavraschave e/ou termos específicos indexados: "história"e "historiografia" em combinação com o termo "Educação Física" e foram selecionadas 36 publicações. Essa busca foi restrita a estudos publicados em Português e no Brasil. O critério de exclusão tinha como condição que a publicação não estivesse no SCIELO ou que não passasse por revisão feita em pares. Os artigos foram examinados e discutidos pelos tipos de métodos, abordagem, concepções e perspectivas, conforme proposta de Barbieri, Porelli e Mello (2008) e os seguintes critérios metodológicos foram analisados: i) o processo de análise crítica das fontes; ii) comprovações de testemunhos e veracidade de histórias orais, e; iii) testemunho indireto.

\section{Resultados}

A Tabela 1 mostra os estudos encontrados na base de dados com o respectivo título, método utilizado e abordagem, concepção ou perspectiva. 
Tabela 1.: Descrição do estudo, título, método de pesquisa utilizado e abordagem, concepção ou perspectiva dos autores.

\begin{tabular}{|c|c|c|c|}
\hline Estudo & Título & Método & Abordagem/concepção/perspectiva \\
\hline $\begin{array}{l}\text { Godoi e Neves } \\
\text { (2012) }\end{array}$ & $\begin{array}{l}\text { Corpo, violência sexual, } \\
\text { vulnerabilidade e educação } \\
\text { libertadora no filme } \\
\text { "Preciosa: uma história de } \\
\text { esperança" }\end{array}$ & $\begin{array}{l}\text { Análise de } \\
\text { fontes }\end{array}$ & $\begin{array}{l}\text { Analisa as representações de corpo } \\
\text { (raça, obesidade e beleza), de } \\
\text { violência sexual e os aspectos de } \\
\text { vulnerabilidade, educação e } \\
\text { emancipação vividos pela protagonista } \\
\text { na trama do filme "Preciosa: uma } \\
\text { história de esperança". }\end{array}$ \\
\hline Dias(2014) & $\begin{array}{l}\text { Momentos iniciais da } \\
\text { educação física em Goiás } \\
(1917-1929)\end{array}$ & $\begin{array}{l}\text { Análise de } \\
\text { fontes }\end{array}$ & $\begin{array}{l}\text { Analisa os momentos iniciais da } \\
\text { organização institucional da Educação } \\
\text { Física em escolas de Goiás, valendo-se } \\
\text { de legislações, jornais, fotografias, } \\
\text { livros de memórias e documentos } \\
\text { oficiais como fontes. }\end{array}$ \\
\hline $\begin{array}{l}\text { Kaminski e } \\
\text { Goellner (2010) }\end{array}$ & $\begin{array}{l}\text { Corpo discente em } \\
\text { movimento: reivindicações } \\
\text { estudantis na Escola Superior } \\
\text { de Educação Física do Rio } \\
\text { Grande do Sul (1957-1964) }\end{array}$ & $\begin{array}{l}\text { Análise de } \\
\text { fontes }\end{array}$ & $\begin{array}{l}\text { Analisa a ação de estudantes da Escola } \\
\text { de Educação Física do Rio Grande do } \\
\text { Sul entre os anos de } 1957 \text { e } 1964 .\end{array}$ \\
\hline $\begin{array}{l}\text { Rosário e Darido } \\
\text { (2012) }\end{array}$ & $\begin{array}{l}\text { Os conteúdos escolares das } \\
\text { disciplinas de história e } \\
\text { ciências e suas relações com } \\
\text { a organização curricular da } \\
\text { Educação Física na escola }\end{array}$ & $\begin{array}{l}\text { Análise de } \\
\text { fontes }\end{array}$ & $\begin{array}{l}\text { Investiga as relações entre os } \\
\text { conteúdos das disciplinas de História e } \\
\text { Ciências com a Educação Física. }\end{array}$ \\
\hline $\begin{array}{l}\text { Silva e Fraga } \\
\text { (2014) }\end{array}$ & $\begin{array}{l}\text { A história da Educação Física } \\
\text { na educação profissional: } \\
\text { entrada, saída e retorno à } \\
\text { Escola Federal de Porto } \\
\text { Alegre }\end{array}$ & $\begin{array}{l}\text { Análise de } \\
\text { fontes }\end{array}$ & $\begin{array}{l}\text { Analisa documentos relativos ao } \\
\text { ensino ministrado nesta instituição de } \\
\text { ensino entre os anos de } 1966 \text { e } 2012 \text {. }\end{array}$ \\
\hline Soares(2011) & $\begin{array}{l}\text { As roupas destinadas aos } \\
\text { exercícios físicos e ao } \\
\text { esporte: nova sensibilidade, } \\
\text { nova educação do corpo } \\
\text { (Brasil, 1920-1940) }\end{array}$ & $\begin{array}{l}\text { Análise de } \\
\text { fontes }\end{array}$ & $\begin{array}{l}\text { Analisa reportagens e imagens } \\
\text { publicadas em revistas brasileiras } \\
\text { pertencentes ao domínio da educação } \\
\text { física e do esporte entre os anos de } \\
1920 \text { e } 1940 \text { e tem como objetivo } \\
\text { compreender as justificativas } \\
\text { elaboradas para o uso de roupas } \\
\text { específicas nessas práticas, em suas } \\
\text { dimensões higiênicas, morais e } \\
\text { estéticas, presentes nos argumentos } \\
\text { desenvolvidos no período. }\end{array}$ \\
\hline Rosa e Leta (2010) & $\begin{array}{l}\text { Tendências atuais da } \\
\text { pesquisa brasileira em } \\
\text { Educação Física Parte 1: uma } \\
\text { análise a partir de periódicos } \\
\text { nacionais }\end{array}$ & Bibliometria & $\begin{array}{l}\text { Analisa a disciplina de Educação } \\
\text { Física em relação a tradicional } \\
\text { valorização de aspectos biológicos } \\
\text { e médicos e, de outro, com a } \\
\text { recente valorização de aspectos } \\
\text { socioculturais, políticos e } \\
\text { filosóficos. }\end{array}$ \\
\hline $\begin{array}{l}\text { Prazedes e } \\
\text { Peduzzi (2009) }\end{array}$ & $\begin{array}{l}\text { TychoBrahe e Kepler na } \\
\text { escola: uma contribuição à } \\
\text { inserção de dois artigos em } \\
\text { sala de aula }\end{array}$ & $\begin{array}{l}\text { Ensaio } \\
\text { crítico- } \\
\text { reflexivo }\end{array}$ & $\begin{array}{l}\text { Reflexão epistemológica acerca do } \\
\text { potencial educativo de dois artigos: } \\
\text { "Entrevista com TychoBrahe" e } \\
\text { "Entrevista com Kepler - do seu } \\
\text { nascimento à descoberta das duas } \\
\text { primeiras leis". }\end{array}$ \\
\hline
\end{tabular}




\begin{tabular}{|c|c|c|c|}
\hline Estudo & Título & Método & Abordagem/concepção/perspectiva \\
\hline Kahn (2014) & $\begin{array}{l}\text { Lições de coisas e ensino das } \\
\text { ciências na França no fim do } \\
\text { século 19: contribuição a } \\
\text { uma história da cultura }\end{array}$ & $\begin{array}{l}\text { Ensaio } \\
\text { crítico- } \\
\text { reflexivo }\end{array}$ & $\begin{array}{l}\text { Analisa grandes reformas realizadas } \\
\text { na organização institucional da escola } \\
\text { primária, gratuidade, obrigação, } \\
\text { laicidade, os republicanos franceses do } \\
\text { final do século } 19 \text { quiseram operar } \\
\text { uma profunda transformação dos } \\
\text { conteúdos de ensino e das normas } \\
\text { pedagógicas. }\end{array}$ \\
\hline $\begin{array}{l}\text { Nahas e Garcia } \\
(2010)\end{array}$ & $\begin{array}{l}\text { Um pouco de história, } \\
\text { desenvolvimentos recentes e } \\
\text { perspectivas para a pesquisa } \\
\text { em atividade física e saúde } \\
\text { no Brasil }\end{array}$ & $\begin{array}{l}\text { Ensaio } \\
\text { crítico- } \\
\text { reflexivo }\end{array}$ & $\begin{array}{l}\text { Discute desenvolvimentos recentes e } \\
\text { perspectivas na pesquisa em atividade } \\
\text { física e saúde, com repercussões para a } \\
\text { Educação Física no Brasil. }\end{array}$ \\
\hline $\begin{array}{l}\text { Oliveira e } \\
\text { Linhares (2011) }\end{array}$ & $\begin{array}{l}\text { Pensar a educação do corpo } \\
\text { na e para a escola: indícios } \\
\text { no debate educacional } \\
\text { brasileiro (1882-1927) }\end{array}$ & $\begin{array}{l}\text { Ensaio } \\
\text { crítico- } \\
\text { reflexivo }\end{array}$ & $\begin{array}{l}\text { Analisa disciplinas escolares e outras } \\
\text { práticas educativas realizadas na } \\
\text { escola e em seu entorno, algumas com } \\
\text { impressionante permanência. Tendo a } \\
\text { educação do corpo como escopo } \\
\text { básico, essas disciplinas e práticas } \\
\text { delinearam um verdadeiro projeto de } \\
\text { intervenção cultural. }\end{array}$ \\
\hline $\begin{array}{l}\text { Rechieli,Porto e } \\
\text { Moreira (2008) }\end{array}$ & $\begin{array}{l}\text { Corpos deficientes, eficientes } \\
\text { e diferentes:uma visão a } \\
\text { partir da Educação Física }\end{array}$ & $\begin{array}{l}\text { Ensaio } \\
\text { crítico- } \\
\text { reflexivo }\end{array}$ & $\begin{array}{l}\text { Analisa o ser humano classificado por } \\
\text { seu corpo deficiente no passado, } \\
\text { eficiente no presente e diferente no } \\
\text { futuro }\end{array}$ \\
\hline $\begin{array}{l}\text { Souza Júnior e } \\
\text { Darido (2010) }\end{array}$ & $\begin{array}{l}\text { Refletindo sobre a } \\
\text { tematização do futebol na } \\
\text { Educação Física escolar }\end{array}$ & $\begin{array}{l}\text { Ensaio } \\
\text { crítico- } \\
\text { reflexivo }\end{array}$ & $\begin{array}{l}\text { Discute um conjunto de temas } \\
\text { relevantes do conteúdo futebol que } \\
\text { possam servir de subsídios para } \\
\text { propostas de sistematização para o } \\
\text { componente curricular Educação } \\
\text { Física escolar. }\end{array}$ \\
\hline $\begin{array}{l}\text { Fialho et al. } \\
\text { (2014) }\end{array}$ & $\begin{array}{l}\text { O imaginário coletivo de } \\
\text { estudantes de educação física } \\
\text { sobre vida saudável }\end{array}$ & Entrevista & $\begin{array}{l}\text { Investiga o imaginário coletivo de } \\
\text { estudantes de Educação Física sobre a } \\
\text { vida saudável. }\end{array}$ \\
\hline $\begin{array}{l}\text { Lehnhard, Marta, } \\
\text { Palma (2012) }\end{array}$ & $\begin{array}{l}\text { A prática de atividade física } \\
\text { na história de vida de pessoas } \\
\text { com deficiência física }\end{array}$ & Entrevista & $\begin{array}{l}\text { Investiga a prática de atividades físicas } \\
\text { de pessoas com deficiência física em } \\
\text { diferentes fases da vida }\end{array}$ \\
\hline $\begin{array}{l}\text { Devideet al. } \\
\text { (2011) }\end{array}$ & $\begin{array}{l}\text { Estudos de gênero na } \\
\text { Educação Física Brasileira }\end{array}$ & $\begin{array}{l}\text { Estado da } \\
\text { arte }\end{array}$ & $\begin{array}{l}\text { Mapeia alguns aspectos relativos ao } \\
\text { quadro teórico dos estudos de gênero } \\
\text { na Educação Física (EF) no Brasil: } \\
\text { correntes teóricas, temáticas } \\
\text { recorrentes, lacunas, grupos de } \\
\text { pesquisa e intelectuais cadastrados no } \\
\text { CNPq, além dos livros sobre Gênero } \\
\text { na EF e esporte. }\end{array}$ \\
\hline $\begin{array}{l}\text { Lazzarotti Filho, } \\
\text { Silva e Pires } \\
(2008)\end{array}$ & $\begin{array}{l}\text { Saberes e práticas corporais } \\
\text { na formação de professores } \\
\text { de Educação Física na } \\
\text { modalidade à distância }\end{array}$ & $\begin{array}{l}\text { Estudo de } \\
\text { caso }\end{array}$ & $\begin{array}{l}\text { Comunica resultado de uma } \\
\text { investigação para compreender como é } \\
\text { desenvolvido o saber das práticas } \\
\text { corporais num curso de licenciatura } \\
\text { em Educação Física na modalidade à } \\
\text { distância }\end{array}$ \\
\hline $\begin{array}{l}\text { Mazo e Lyra } \\
(2010)\end{array}$ & $\begin{array}{l}\text { Nos rastros da memória de } \\
\text { um "Mestre de Ginástica" }\end{array}$ & $\begin{array}{l}\text { Estudo de } \\
\text { caso }\end{array}$ & $\begin{array}{l}\text { Reconstitui a história de vida de Georg } \\
\text { Black no cenário da educação física e } \\
\text { esportes do Rio Grande do Sul }\end{array}$ \\
\hline
\end{tabular}




\begin{tabular}{|c|c|c|c|}
\hline Estudo & Título & Método & Abordagem/concepção/perspectiva \\
\hline $\begin{array}{l}\text { Góis Junior et al. } \\
\text { (2012) }\end{array}$ & $\begin{array}{l}\text { Estudo histórico sobre a } \\
\text { formação profissional na } \\
\text { Escola de Educação Física e } \\
\text { Esporte da Universidade de } \\
\text { São Paulo (1980-1990) }\end{array}$ & História oral & $\begin{array}{l}\text { Analisa as influências dos debates } \\
\text { sobre educação física dos anos } 1980 \\
\text { no âmbito da Escola de Educação } \\
\text { Física e Esporte (EEFE-USP); em } \\
\text { específico, interessa analisar o } \\
\text { contexto histórico das reformas } \\
\text { curriculares dos anos } 1990 \text { nesta } \\
\text { instituição. }\end{array}$ \\
\hline $\begin{array}{l}\text { Pires, Rocha } \\
\text { Junior e Marta } \\
\text { (2014) }\end{array}$ & $\begin{array}{l}\text { Primeiro curso de Educação } \\
\text { Física na Bahia - trajetórias e } \\
\text { personagens }\end{array}$ & História oral & $\begin{array}{l}\text { Investiga a criação do primeiro curso } \\
\text { superior em Educação Física na Bahia } \\
\text { e objetiva apresentar seus bastidores, } \\
\text { para perceber seus movimentos } \\
\text { políticos e acadêmicos. }\end{array}$ \\
\hline $\begin{array}{l}\text { Silveira et al. } \\
\text { (2011) }\end{array}$ & $\begin{array}{l}\text { Escola de formação de } \\
\text { "professoras": as relações de } \\
\text { gênero no currículo superior } \\
\text { de educação física }\end{array}$ & História oral & $\begin{array}{l}\text { Investiga como as relações de gênero } \\
\text { estiveram presentes na emergência e } \\
\text { na consolidação do currículo da Escola } \\
\text { Superior de Educação Física da } \\
\text { Universidade Federal de Pelotas } \\
\text { (ESEF/UFPel). }\end{array}$ \\
\hline $\begin{array}{l}\text { Abreu Junior e } \\
\text { Carvalho (2012) }\end{array}$ & $\begin{array}{l}\text { O discurso médico-higienista } \\
\text { no Brasil do início do século } \\
\text { XX }\end{array}$ & Historiografia & $\begin{array}{l}\text { Analisa a compreensão da relação } \\
\text { entre higienismo e educação nas } \\
\text { primeiras décadas do século XX no } \\
\text { Brasil. }\end{array}$ \\
\hline $\begin{array}{l}\text { Almeida, Wiggers } \\
\text { e Jubé (2013) }\end{array}$ & $\begin{array}{l}\text { Do corpo produtivo ao corpo } \\
\text { rascunho: aproximações } \\
\text { conceituais a partir de } \\
\text { relações entre corpo e } \\
\text { tecnologia }\end{array}$ & Historiografia & $\begin{array}{l}\text { Examina relações entre "corpo e } \\
\text { tecnologia" no contexto do projeto } \\
\text { social moderno, tomando como } \\
\text { referência as noções de "corpo } \\
\text { produtivo" e "corpo rascunho" }\end{array}$ \\
\hline Goellner (2010) & $\begin{array}{l}\text { Educação física, ciência e } \\
\text { saúde: notas sobre o acervo } \\
\text { do Centro de Memória do } \\
\text { Esporte (UFRGS) }\end{array}$ & Historiografia & $\begin{array}{l}\text { Destaca a relevância do acervo do } \\
\text { Centro de Memória do Esporte e de } \\
\text { suas principais coleções para as } \\
\text { pesquisas sobre a historiografia das } \\
\text { práticas corporais e esportivas e sua } \\
\text { aproximação com a saúde, a educação } \\
\text { e o lazer. }\end{array}$ \\
\hline $\begin{array}{l}\text { Góis Junior, } \\
\text { Lovisolo e Nista- } \\
\text { Piccolo (2013) }\end{array}$ & $\begin{array}{l}\text { Processo Civilizador: } \\
\text { Apontamentos } \\
\text { metodológicos na } \\
\text { historiografia da Educação } \\
\text { Física }\end{array}$ & Historiografia & $\begin{array}{l}\text { Analisa a utilização do modelo } \\
\text { elisiano em problemas de pesquisa no } \\
\text { campo da História da Educação Física }\end{array}$ \\
\hline $\begin{array}{l}\text { Góis Junior, } \\
\text { Lovisolo e Nista- } \\
\text { Piccolo (2013) }\end{array}$ & $\begin{array}{l}\text { Processo Civilizador: } \\
\text { apontamentos metodológicos } \\
\text { na historiografia da } \\
\text { Educação Física }\end{array}$ & Historiografia & $\begin{array}{l}\text { Analisa a utilização do modelo } \\
\text { elisiano em problemas de pesquisa no } \\
\text { campo da História da Educação Física. }\end{array}$ \\
\hline $\begin{array}{l}\text { Herold Júnior e } \\
\text { Vaz (2013) }\end{array}$ & $\begin{array}{l}\text { Representações sobre corpo } \\
\text { e educação da mulher na } \\
\text { expansão do escotismo e do } \\
\text { Bandeirantismo durante nas } \\
\text { primeiras décadas do século } \\
\text { XX }\end{array}$ & Historiografia & $\begin{array}{l}\text { Analisa representações sobre corpo e } \\
\text { educação feminina no interior da } \\
\text { expansão do movimento escoteiro, que } \\
\text { ocorreu nas primeiras décadas do } \\
\text { século XX. }\end{array}$ \\
\hline $\begin{array}{l}\text { Matthiesen, } \\
\text { Ginciene e Freitas } \\
(2012)\end{array}$ & $\begin{array}{l}\text { Registros da maratona em } \\
\text { Jogos Olímpicos para a } \\
\text { difusão em aulas de } \\
\text { Educação Física }\end{array}$ & Historiografia & $\begin{array}{l}\text { Investiga as alterações pelas quais a } \\
\text { maratona passou ao longo dos anos, } \\
\text { visando à difusão desse conhecimento, } \\
\text { especialmente, em aulas de Educação } \\
\text { Física. }\end{array}$ \\
\hline
\end{tabular}




\begin{tabular}{|c|c|c|c|}
\hline Estudo & Título & Método & Abordagem/concepção/perspectiva \\
\hline Oliveira (2001) & $\begin{array}{l}\text { A revista brasileira de } \\
\text { educação física e desportos e } \\
\text { a experiência cotidiana de } \\
\text { professores da rede } \\
\text { municipal de ensino de } \\
\text { Curitiba: entre adesão e a } \\
\text { resistência }\end{array}$ & Historiografia & $\begin{array}{l}\text { Debate o ponto de vista da pesquisa } \\
\text { em história da educação, as relações } \\
\text { entre o aparato legalinstitucional para } \\
\text { a Educação Física brasileira de } 1968 \text { a } \\
1984 \text { e a apropriação dos professores } \\
\text { escolares daquele aparato. }\end{array}$ \\
\hline Oliveira (2002) & $\begin{array}{l}\text { Educação Física escolar e } \\
\text { ditadura militar no Brasil } \\
\text { (1968-1984): história e } \\
\text { historiografia }\end{array}$ & Historiografia & $\begin{array}{l}\text { Discute a recente produção } \\
\text { historiográfica da educação e da } \\
\text { educação física no Brasil sobre a } \\
\text { educação física no período da ditadura } \\
\text { miliar. }\end{array}$ \\
\hline $\begin{array}{l}\text { Schneider et } \\
\text { al.(2014) }\end{array}$ & $\begin{array}{l}\text { A Educação Física, o esporte } \\
\text { e o (pan-)americanismo em } \\
\text { revista (1932-1950) }\end{array}$ & Historiografia & $\begin{array}{l}\text { Investiga a presença americana e do } \\
\text { movimento pan-americanista na } \\
\text { Educação Física brasileira para } \\
\text { compreender de que forma } \\
\text { contribuíram na produção de uma } \\
\text { cultura esportiva na primeira metade } \\
\text { do século XX. }\end{array}$ \\
\hline $\begin{array}{l}\text { Souza Júnior e } \\
\text { Galvão (2005) }\end{array}$ & $\begin{array}{l}\text { História das disciplinas } \\
\text { escolares e história da } \\
\text { educação: algumas reflexões }\end{array}$ & Historiografia & $\begin{array}{l}\text { Identifica e problematiza as tendências } \\
\text { de pesquisa na área da história da } \\
\text { Educação. }\end{array}$ \\
\hline Vago (1999) & $\begin{array}{l}\text { Início e fim do século XX: } \\
\text { Maneiras de fazer educação } \\
\text { física na escola }\end{array}$ & Historiografia & $\begin{array}{l}\text { Discute o enraizamento escolar da } \\
\text { educação física, cotejando-se dois } \\
\text { momentos históricos importantes da } \\
\text { educação: um em Minas Gerais (a } \\
\text { reforma do ensino de 1906) e o outro } \\
\text { no Brasil (os novos ordenamentos } \\
\text { legais). }\end{array}$ \\
\hline $\operatorname{Vaz}(2000)$ & $\begin{array}{l}\text { Da modernidade em Walter } \\
\text { Benjamin: crítica, esporte e } \\
\text { escritura histórica das } \\
\text { práticas corporais }\end{array}$ & Historiografia & $\begin{array}{l}\text { Analisa da concepção da obra de arte, } \\
\text { filosofia, história do autor e } \\
\text { reprodutibilidade moderna das } \\
\text { concepções e sua relação com o } \\
\text { esporte. }\end{array}$ \\
\hline $\begin{array}{l}\text { Stigger, Fraga e } \\
\text { Molina Neto } \\
(2014)\end{array}$ & $\begin{array}{l}\text { Os editoriais contam } \\
\text { histórias: experiências do } \\
\text { ofício de editor na Revista } \\
\text { Movimento }\end{array}$ & $\begin{array}{l}\text { Relato de } \\
\text { experiência }\end{array}$ & $\begin{array}{l}\text { Analisa as experiências relativas ao } \\
\text { ofício de editor da revista Movimento, } \\
\text { periódico da Escola de Educação } \\
\text { Física da Universidade Federal do Rio } \\
\text { Grande do Sul, narradas a partir dos } \\
\text { editoriais que marcaram seus } 18 \text { anos } \\
\text { de existência. }\end{array}$ \\
\hline $\begin{array}{l}\text { Marcon, Graça e } \\
\text { Nascimento (2010) }\end{array}$ & $\begin{array}{l}\text { Estruturantes da base de } \\
\text { conhecimentos para o ensino } \\
\text { de estudantesprofessores de } \\
\text { Educação Física }\end{array}$ & Revisão & $\begin{array}{l}\text { Analisa os possíveis elementos que } \\
\text { auxiliam na estruturação da base de } \\
\text { conhecimentos dos futuros professores } \\
\text { de Educação Física. }\end{array}$ \\
\hline
\end{tabular}

\section{Discussão}

Em relação aos estudos com fontes primárias, todo tipo de fonte pode ser considerada em pesquisa histórica, como, vasos, filmes, impressões digitais, declarações ou cartas (OLDENJØRGENSEN, 1998; THURÉN, 1997). Os artigos brasileiros mostram abordagens de documentos que discutem problemas atuais, analisando artigos de jornais, cartas oficiais da época e ou filmagens que discutem assuntos polêmicos como a concepção das representações do corpo na sociedade através da dialética do corpo belo sob parâmetros social de beleza 
(GODOI; NEVES, 2012) e ou tratam das práticas higienistas e utilitaristas (ROSA; LETA, 2010; SOARES, 2011; DIAS, 2014). Outras investigações marcam um fluente debate de ordem cronológica que criam condições para o desenvolvimento da disciplina na ordem política e organizacional da Educação Física e uma não menos importante renovação de seu campo de investigação metodológica, como as discussões críticas relacionadas com as ações estudantis e reivindicações sobre a organização curricular da Educação Física (KAMINSKI; GOELLNER, 2010). Essa análise crítica dos profissionais da área sobre o currículo também é tema de outra pesquisa com foco nos últimos 50 anos da área de estudo (SILVA; FRAGA, 2014).

Dentre os artigos encontrados com análise de fontes, 50\% é compostos por histórias orais ou entrevistas, como mostra a tabela 1. Em grande parte, discutem sobre a concepção da Educação Física como disciplina escolar e sobre a formação profissional nessa área (MAZO; LYRA, 2010; GÓIS JUNIOR et al., 2012; PIRES, ROCHA JUNIOR; MARTA, 2014; SILVEIRA et al., 2011). Quanto mais perto da fonte é o momento de investigação do evento que se pretende discutir, maior é a confiabilidade desse documento ou testemunho, pois é possível relatar uma descrição mais exata do fato histórico (OLDEN-JØRGENSEN, 1998; THURÉN, 1997). As discussões sobre o currículo escolar e a disciplina de Educação Física são as mais frequentes nos estudos (Tabela 1), as quais revelam a pretensão social de utilizar essa disciplina enquanto processo higienista e higienizador, desde a implantação da cadeira, com orientações feitas inicialmente por militares, até os dias de hoje, na tentativa de combater a fadiga intelectual das crianças e o tédio das práticas escolares vigentes (VAGO, 1999). Para datas mais distantes, como no estudo de Dias (2014), que trata do início do século XIX, são utilizados, com maior foco, documentos oficiais ou públicos, como legislações, artigos em jornais, fotografias, livros de memória para contextualizar a organização institucional da Educação Física nas escolas. É importante destacar que apesar de serem poucas, as pesquisas brasileiras apresentadas com análise de fontes primárias evitam qualquer dado forjado ou corrompido com o uso de documentos oficiais ou publicados, esses fortes indícios da originalidade da fonte aumentam o seu grau de confiabilidade (OLDEN-JØRGENSEN, 1998; THURÉN, 1997).

Apesar de historiografias discutirem as percepções sobre as mudanças culturais, históricas e políticas da Educação Física ao longo de todo o século XX até os dias de hoje, a marca do higienismo permanece latente na disciplina. Assim também nas discussões dos estudos apresentados (Tabela 1) que mostram ensaios críticos-reflexivos sobre estudos de caso e sobre a constituição e o ideal de formação de um novo homem para uma consequente nova sociedade. As investigações apresentam testemunhos e fontes primárias ricas em informações, o que também garante a confiabilidade das análises, quando comparado com o uso de fontes secundárias ou terciárias (THURÉN, 1997).

Soares (2011), por exemplo, mostra como o uso variado de fontes independentes com mensagens comuns pode garantir elevada credibilidade ao estudo. Alguns autores indicam que para controle dos métodos de pesquisa, as tendenciosidades de análise de fontes devem ser minimizadas ou suplementadas com fatos opostos (OLDEN-JØRGENSEN, 1998). Investigações com história oral mostram testemunhos importantes para compreensão de determinados contextos históricos (OLIVEIRA, 2004), mas não se sabe ao certo se esses participantes teriam ou não interesse direto na criação de viés. O controle desse tipo de fator aumentaria a credibilidade do estudo (OLDEN-JØRGENSEN, 1998). 
Através da análise metodológica dos artigos publicados, pode-se apontar procedimentos comuns para estabelecer crítica externa e interna das diferentes fontes utilizadas: i) quando as fontes concordam sobre um evento, os pesquisadores consideraram o evento provado (SOARES, 2011); ii) a maioria dos estudos apresentados na Tabela 1 excluiu fontes com relatos únicos, após uma análise crítica textual, mesmo que a maioria das fontes seja relacionada com eventos de uma maneira, essa única fonte que discorda do fato não deve permanecer no estudo, a menos que passe em um teste de análise textual crítica; iii)documentos não oficiais, como cartas pessoais, foram consideradas confiáveis através de testemunhos que confirmassem o fato histórico; iv)quando duas fontes discordaram em um ponto específico, o pesquisador debateu e mostrou preferência em utilizar a fonte com mais "autoridade", isto é, a fonte criada pelo perito ou por uma testemunha ocular; v)as entrevistas e histórias orais com mais autoridade no assunto abordado foram, em geral, preferidas, especialmente em circunstâncias em que o observador poderia ter relatos ordinários com precisão no que aconteceu e, mais especificamente, quando eles lidam com fatos conhecidos pela maioria dos contemporâneos (MAZO; LYRA, 2010); vi)se duas fontes independentes concordaram sobre uma questão, a confiabilidade de cada uma análise dos fatos é reforçada (SILVEIRA et al., 2011) evii) quando duas fontes discordaram e não há outros meios de avaliação, o pesquisador utilizou a que seria mais provável de acontecer (PIRES; ROCHA; MARTA, 2014). Essas abordagens metodológicas corroboram os estudos prévios que discutem críticas ao método de análise de fontes em pesquisas históricas (BERNHEIM, 1889; LANGLOIS; SEIGNOBOS, 1898).

Em relação à preocupação com a autenticidade e procedência, quando a fonte foi escrita ou não foi produzido no período analisado, observou-se uma preocupação eminente no número de documentos e nas pesquisas observadas em relação ao fato que se pretende discutir nas investigações brasileiras apresentadas na Tabela 1.

As historiografias do presente estudo apresentaram críticas bem fundamentadas, desde em relação aos modelos elisianos até a relevância dos acervos nacionais sobre práticas corporais e esportivas para a saúde, educação e lazer (GOELLNER, 2010). Outras,mostraram a conexão contextual da Educação Física aos marcos na história social e política do país, como a ditadura militar, e trazem consigo o tempo combinado com a localização, o que também garante uma crítica externa do estudo (OLIVEIRA, 2001; OLIVEIRA, 2002). A análise da concepção de obras, experiências e ações de pessoas (relato de experiência e estudos de caso) (VAZ, 2000), assim como de grupos (SCHNEIDERet al., 2014), éabordagem polêmica nas investigações, uma vez que mostrou maior número em contribuições na produção cultural da área da Educação Física.

Por sua vez, a autoria dos estudos originais investigados na historiografia em alguns momentos não é mostrada, o que pode ser uma limitação relacionada com da integridade da fonte (GOTTSCHALK, 1950). Entretanto, o valor probatório do conteúdo, a credibilidade dos estudos é mantida, por serem artigos publicados em revista da área de Educação Física (OLIVEIRA, 2001; ALMEIDA; WIGGER; JUBÉ, 2013).A percepção subjetiva dos sujeitos entrevistados ou de testemunhas nas histórias orais e entrevistas são discutidas por relatos comuns (SHAFER, 1974). Por seu lado, as análises realizadas com fatos históricos privilegiaram o papel do observador em relação ao fato estudado,o que reduz a possibilidade de existir viés e tendensiodades(GÓIS JUNIORet al., 2012; SILVEIRA et al., 2011).

Algumas recomendações para investigações futuras poderiam incluir tanto a capacidade de relatar do observador entrevistadocomo o local da entrevista, além do momento do fato (distante 
ou próximo) em relação ao contexto presencial, pois podem influenciar os testemunhos. Inclusive, diferentes pesquisas da Tabela 1 tratam de períodos distantes do presente, o que pode influenciar a acurácia da pesquisa, pois muitos sujeitos do período estudado, como no começo e meio do século XX, podem estar mortos e materiais relevantes para compreensão do fato podem estar extintos (SHAFER, 1974).

Outras questões em relação às entrevistas e histórias orais precisam ser verificadas, tais como a intenção do entrevistado ao relatar um acontecimento, para quem ele relata e se o público será suscetível em exigir ou sugerir alguma distorção por parte do observador (SHAFER, 1974). Nas histórias orais apresentadas na Tabela 1, muitas das informações vêm de "testemunhas indiretas", ou seja, as pessoas entrevistadas não estavam presentes na cena, mas ouviram falar dos eventos a partir de outra pessoa (GARRAGHAN, 1946). Gottschalk(1950) indica que um historiador pode, por vezes, usar evidência de boato,no entanto, nos casos em que se utilizam testemunhas secundárias avalia-se testemunhos primários e se estão de acordo com declarações secundárias (GOTTSCHALK, 1950).

Em grande parte dos estudos apresentados com histórias orais, a fonte secundária é fonte "original" do pesquisador, no sentido de ser a "origem" de seu conhecimento.N a medida em que esta fonte "original" é um relatório preciso do testemunho primário,a credibilidade da investigação como se fosse um testemunho primário é atestada (BEHAN; MCCULLAGH, 1984; GARRAGHAN, 1946; GOTTSCHALK, 1950). Isso se explicitanas histórias orais que explicaram as influências dos debates da Educação Física dos anos 1980 no âmbito da Escola de Educação Física e Esporte e a observação das declarações comuns sobre suas consequências no contexto histórico das reformas curriculares dos anos 1990 nesta instituição(GÓIS JUNIOR et al., 2012).

\section{Conclusão}

A maior compreensão sobre os métodos utilizados na história e a historiografia na Educação Física diagrama as temáticas para a formação de novos estudos. Diversos elementos comuns são observados nas pesquisas brasileiras, os quais garantem a credibilidade e a confiabilidade desse tipo de estudo. Uma extensa discussão pode ser feita em relação às diferentes temáticas tratadas pelas pesquisas atuais, as quais ordenam razões sobre o uso das atividades corporais e explicam a origem e as mudanças políticas na Educação Física.Outras mostram as modificações dos métodos e sistematizações das aulas ministradas na cadeira escolar e também abordam assuntos polêmicos, como a ditadura militar, com impactos socioculturais das e pelas práticas físicas. Os elementos tratados na Educação Física e articulados com outras temáticas aguçam novos estudos e tornam atrativa a área para estudo.

\section{Referências}

ALMEIDA, D.F.; WIGGERS, I.D.; JUBÉ, C.N. Do corpo produtivo ao corpo rascunho: aproximações conceituais a partir de relações entre corpo e tecnologia. Revista Sociedade e Estado, Brasília, v.29, n 3, p.963-83, set./dez. 2014. https://doi.org/10.1590/S0102-69922014000300014 
DEVIDE, F.P. et al. Estudos de gênero na Educação Física Brasileira. Motriz, Rio Claro, v.17 n.1, p.93-103, jan./mar. 2011.

DIAS, C. Momentos iniciais da educação física em Goiás (1917-1929). Revista Brasileira de Educação Física e Esporte, São Paulo, v.28, n.1, jan./mar. 2014.

FIALHO et.al. O imaginário coletivo de estudantes de educação física sobre vida saudável. Revista Brasileira de Ciênciae Esporte, Florianópolis, v.36, n.3, 2014.

GILBERT J.; GARRAGHAN, A. Guide to Historical Method. FordhamUniversity Press, New York, 1946, 272 p.

GODOI, M.R.; NEVES, L. Body, sexual violence, vulnerability and liberation education in the film "Precious: based on the novel 'push' by sapphire". Interface - Comunicação, Saúde, Educação, v.16, n.41, p.409-21, abr./jun. 2012. https://doi.org/10.1590/S1414-32832012005000030

GOELLNER, S.ilvana V. Educação física, ciência e saúde: notas sobre o acervo do Centro de Memória do Esporte (UFRGS). História, Ciências e Saúde, Rio de Janeiro, v.17, n.2, p.527536, abr.-jun. 2010.

GÓIS JUNIOR, E. Estudo histórico sobre a formação profissional na Escola de Educação Física e Esporte da Universidade de São Paulo (1980-1990). Motriz, Rio Claro, v.18 n.2, p.393-400, abr./jun. 2012.

GÓIS JUNIOR, E.; LOVISOLO,H.R.; NISTA-PICCOLO, V.L. Processo Civilizador: Apontamentos metodológicos na historiografia da Educação Física. Revista Brasileira Ciência e Esporte, Florianópolis, v.35, n.3, p.773-783, jul./set. 2013. https://doi.org/10.1590/S0101-32892013000300017

GOTTSCHALK,L. Understanding History: A Primer of Historical Method.Alfred A. Knopf, New York,1950, 167p.

HEROLD JUNIOR, C. A educação física do ponto de vista da história. Revista Educação Física/UEM, Maringá, v.8(1), p.59-71, 1997.

HOWELL, M.; PREVENIER, W. From Reliable Sources: An Introduction to Historical Methods.Cornell University Press, Ithaca, 2001, 224p.

KAHN,P. Lições de coisas e ensino das ciências na França no fim do século 19: contribuição a uma história da cultura, História da Educação (online), Porto Alegre, v. 18, n. 43,p. 183-201, mai./ago. 2014.

KAMINSKI, L.F.; GOELLNER, S.V.Corpo discente em movimento: reivindicações estudantis na Escola Superior de Educação Física do Rio Grande do Sul (1957-1964). Motriz, Rio Claro, v.16 n.4 p.984-994, out./dez. 2010.

LAZZAROTTI FILHO, A.; SILVA, A.M.; e PIRES, G.L. Saberes e práticas corporais na formação de professores de Educação Física na modalidade a distância. Revista Brasileira Ciência e Esporte, Florianópolis, v.35, n.3, p. 701-715, jul./set. 2013. https://doi.org/10.1590/S0101-32892013000300013 
LEHNHARD, G.R.;MANTA, Sofia W.;PALMA, Luciana E. A prática de atividade física na história de vida de pessoas com deficiência física. Revista Educação Física/UEM, Maringá, v. 23, n. 1, p. 45-56, 1. trim. 2012.

MARCON, D.; GRAÇA, A.B.S.; NASCIMENTO, J.V. MARCON. Graça e Nascimento Estruturantes da base de conhecimentos para o ensino de estudantesprofessores de Educação Física. Motriz, Rio Claro, v.16 n.3 p.776-787, jul./set. 2010.

MATTHIESEN, S.Q.; GINCIENE, G.; FREITAS, F.P.R. Registros da maratona em Jogos Olímpicos para a difusão em aulas de Educação Física. Revista Brasileira de Educação Física e Esporte, São Paulo, v.26, n.3, p.463-71, jul./set. 2012. https://doi.org/10.1590/S1807-55092012000300012

MAZO, J.Z.; LYRA, V.B. Nos rastros da memória de um "Mestre de Ginástica". Motriz, Rio Claro, v.16, n.4, p.967-976, out./dez. 2010.

McCULLGH C. B. Justifying Historical Descriptions.Cambridge University Press, New York, 1984, 264p.

NAHAS, M.V.; GARCIA,L.M.T.Um pouco de história, desenvolvimentos recentes e perspectivas para a pesquisa em atividade física e saúde no Brasil.Revista Brasileira de Educação Física e Esporte, São Paulo, v.24, n.1, p.135-48, jan./mar. 2010. https://doi.org/10.1590/S1807-55092010000100012

OLIVEIRA, M.A.T. A Revista Brasileira de Educação Física e Desportos e a experiência cotidiana de professores da rede Municipal de Ensino de Curitiba: entre adesão e a resistência. Educar, Curitiba, n. 18, p. 239-247. 2001.

OLIVEIRA, M.A.T. Educação Física escolar e ditadura militar no Brasil (1968-1984): história e historiografia. Educação e Pesquisa, São Paulo, v.28, n.1, p. 51-75, jan./jun. 2002. https://doi.org/10.1590/S1517-97022002000100004

OLIVEIRA, M.A.T.; LINHARES, M.A. Pensar a educação do corpo na e para a escola: indícios no debate educacional brasileiro (1882-1927). Revista Brasileira de Educação, v. 16, n. 47, p. 389-407, mai./ago. 2011.

PIRES, R.G.; ROCHA JUNIOR, C.P.; MARTA. F.E.F. Primeiro curso de Educação Física na Bahia - trajetórias e personagens. Revista Brasileira Ciência e Esporte, Florianópolis, v. 36, n. 1, p. 205-223, jan./mar. 2014. https://doi.org/10.1590/S0101-32892014000100014

PRAXEDES, G.; PEDUZZI, L.O.Q.TychoBrahe e Kepler na escola: uma contribuição à inserção de dois artigos em sala de aula. Revista Brasileira de Ensino de Física, v. 31, n. 3, 2009.

RECHIELI, A.; PORTO, E.T.R.; MOREIRA, W.W. Corpos deficientes, eficientes e diferentes:uma visão a partir da Educação Física. Revista Brasileirade Educação Especial, Marília, v.14, n.2, p.293-310, mai./ago. 2008.

ROSA, S; LETA, J. Tendências atuais da pesquisa brasileira em Educação Física Parte 1: uma análise a partir de periódicos nacionais. Revista Brasileira de Educação Física e Esporte, São Paulo, v.24, n.1, p.121-34, jan./mar. 2010. https://doi.org/10.1590/S1807-55092010000100011 
ROSÁRIO, L.F.R.; DARIDO, S.C. Os conteúdos escolares das disciplinas de história e ciências e suas relações com a organização curricular da Educação Física na escola. Revista Brasileira de Educação Física e Esporte, São Paulo, v.26, n.4, p.691-704, out./dez. 2012. https://doi.org/10.1590/S1807-55092012000400013

SCHNEIDER, O.; SANTOS, W.; FERREIRA NETO, A.; ASSUNÇÃO, W.R. A educação física, o esporte e o (pan-) americanismo em revista (1932-1950). Revista Educação Física/UEM, v. 25, n. 2, p. 245-256, 2. trim. 2014.

SHAFER R.J. A Guide to Historical Method.The DorseyPress, Illinois,1974, 272 p.

SILVA, E.M.; FRAGA, A.B. A história da Educação Física na educação profissional: entrada, saída e retorno à Escola Federal de Porto Alegre. Revista Brasileira de Educação Física e Esporte, São Paulo, v.28, n.2, abr./jun. 2014.

SILVEIRA et.al. Escola de formação de "professoras": as relações de gênero no currículo superior de Educação Física. Revista Brasileira Ciência e Esporte, Florianópolis, v. 33, n. 4, p. 857-872, out./dez. 2011.

SOARES, C.L. As roupas destinadas aos exercícios físicos e ao esporte: nova sensibilidade, nova educação do corpo (Brasil, 1920-1940). Pro-Posições, Campinas, v. 22, n. 3 (66), p. 8196, set./dez. 2011.

SOUZA JÚNIOR, N.; GALVÃO, A.M.O. História das disciplinas escolares e história da educação: algumas reflexões. Educação e Pesquisa, São Paulo, v. 31, n. 3, p. 391-408, set./dez. 2005. https://doi.org/10.1590/S1517-97022005000300005

SOUZA JÚNIOR, O. M.; DARIDO, S.C. Refletindo sobre a tematização do futebol na Educação Física escolar. Motriz, Rio Claro, v.16 n.4 p.920-930, out./dez. 2010.

STIGGERA, M.P.; FRAGAB A.B.; MOLINA NETO, V. Os editoriais contam histórias: experiências do ofício de editor na Revista Movimento.Revista Brasileira Ciência e Esporte, v.36, n.4, p. 790-801, 2014. https://doi.org/10.1016/j.rbce.2014.11.013

VAGO, T.M. Início e fim do século XX: Maneiras de fazer educação física na escola. Cadernos Cedes, ano XIX, n 48, p.30-51, ago.1999 .

VAZ, A.F. Da modernidade em Walter Benjamin: crítica, esporte e escritura histórica das práticas corporais. Educar, Curitiba, n. 16, p. 61-79. 2000. 